\title{
RESPONSABILIDADE CIVIL DOS HOSPITAIS E OS ÍNDICES DE CONTROLE DE INFECÇÃO HOSPITALAR
}

Natali Scremin ${ }^{1}$

\begin{abstract}
RESUMO: A relação paciente versus hospital é regida pela Lei $\mathrm{n}^{\circ}$ 8.078/90, a qual, sem novidade, é bastante favorável ao consumidor. Em razão disso, vislumbram-se nos Tribunais Pátrios indenizações exorbitantes a serem suportadas pelas instituições de saúde, na hipótese de infecção hospitalar, mesmo quando a instituição de saúde providenciou as devidas medidas sanitárias. Nessa situação, percebe-se circunstância injusta, pois a infecção hospitalar embora seja controlável, não pode ser evitada em absoluto, com a tecnologia e os meios disponíveis atualmente. Desse modo, defende-se neste trabalho a redução do valor da indenização e até mesmo a exclusão da responsabilidade do estabelecimento, nos casos de infecção hospitalar, quando implantado programa de controle da infecção e obtidos índices satisfatórios.
\end{abstract}

PALAVRAS-CHAVE: Responsabilidade. Hospital. Infecção.

\section{Civil Liability of the Hospitals and the Indices of Control of Hospital Infection}

ABSTRACT: The patient relation versus hospital is conducted by the Law $n^{\circ} 8,078 / 90$, which, without newness, is sufficiently favorable to the consumer. In reason of this, excessive indemnities are glimpsed in the Native Courts to be supported for the health institutions, in the hypothesis of hospital infection, exactly when the health institution provided the due sanitary measures. In this situation, unjust circumstance is perceived, therefore the hospital infection even so is controlable, cannot be prevented in absolute, with the available technology and ways currently. In this manner, the reduction of the value of the indemnity is defended even though in this work and the exclusion of the responsibility of the establishment, in the cases of hospital infection, when implanted program of control of the infection and gotten satisfactory indices.

KEY-WORDS: Responsibility. Hospital. Infection.

\section{INTRODUÇÃO}

O tema responsabilidade civil oferece vasto campo de pesquisa e discussões, até porque é freqüentemente abordado nos Tribunais. A análise da jurisprudência e da doutrina brasileira revela tendência mundial de ampliar o campo da responsabilidade objetiva, isto é, aquela que prescinde da prova da culpa, imputando a responsabilidade aos agentes oferecedores do serviço ou criadores do risco.

A principal justificativa para essa ampliação, segundo Sílvio de Salvo Venosa (2005, p. 22) é que "muito cedo se percebeu, no curso da história, que os princípios da responsabilidade com culpa eram insuficientes para muitas das situações de prejuízo, a começar pela dificuldade da prova da própria culpa".

Assim, propõe-se, por meio deste trabalho examinar, sob o ponto de vista jurídico, a responsabilidade dos hospitais nos casos de infecção hospitalar. Alerta-se que

\footnotetext{
${ }^{1}$ Acadêmica do Curso de Direito da Universidade Federal de Santa Maria.

ISSN 1981-3694

(C) 2008. Departamento de Direito da UFSM. Todos os direitos reservados.
} 
o uso da palavra hospital ou qualquer sinônimo, abrange clínicas, pronto-atendimentos, e instituições de saúde em geral.

Para muitos a infecção hospitalar é assunto distante, pois, por sorte, nunca ou pouco se freqüentou um nosocômio, ficando desse modo alijado dessa realidade perturbadora. Quem acompanha mais de perto a rotina dos hospitais, sabe que o combate à infecção hospitalar mais que exigência legal é uma necessidade, dada a importância desse procedimento.

O controle da infecção hospitalar é fundamental, porque ignorar essa necessidade implica no desenvolvimento de um trabalho inócuo nas casas de saúde. Em outros termos, significa conceder o tratamento e/ou a cura para o paciente que procura o estabelecimento e, ao mesmo tempo, entregar-lhe doença ainda mais grave. É o remédio e o veneno.

A infecção hospitalar, também denominada infecção institucional, nosocomial ou Infecções Relacionadas à Assistência à Saúde (IRAS), consiste, segundo definição legal $^{2}$, em qualquer infecção adquirida após a internação do paciente em hospital e que se manifeste durante a internação ou mesmo após a alta, quando puder ser relacionada com a hospitalização ${ }^{3}$. A infecção, geralmente, acarreta moléstia mais grave ao paciente, podendo levar ao seu óbito. Logo, por óbvio, esse problema deve ser evitado, na verdade, minorado, pois impossível obter índice zero dessa infecção.

Por conseguinte, em razão da importância do tema, já que envolve diretamente a saúde, direito fundamental pelo qual todos devem zelar, apresenta-se pertinente realizar algumas considerações sobre $\mathrm{o}$ assunto.

Com fundamento na doutrina e, principalmente nas decisões dos Pretórios, será abordada a responsabilidade civil dos estabelecimentos de saúde nos casos de infecção hospitalar e a influência dos índices de infecção na imputação da responsabilidade e do quantum indenizatório.

\section{A INFECÇÃO HOSPITALAR NA LEGISLAÇÃO}

\footnotetext{
${ }^{2}$ Art. $2^{\circ}, \S 1^{\circ}$, da Lei ${ }^{\circ} 9.431 / 97$.

3 No Brasil, o período de incubação padronizado para as infecções hospitalares é após 72 horas de internação. Após a alta do paciente, as infecções são consideradas hospitalares se manifestadas até 72 horas, em caso de procedimentos cirúrgicos até 30 dias do ato, e, se houve implante, considera-se até um ano.
}

(C) 2008. Departamento de Direito da UFSM. Todos os direitos reservados. 
De plano, insta traçar um breve escorço histórico sobre o controle de infecção hospitalar na legislação pátria.

O Ministério da Saúde passou a preocupar-se com a infecção hospitalar e a tomar medidas para controlá-la somente em 1983. Porém, estudos e providências mais consistentes só foram realizados a partir da comoção popular provocada pela morte do presidente Tancredo Neves, em 1985, que teria sido acometido por infecção hospitalar, a qual agravou o seu estado clínico levando-o a óbito.

A primeira regulamentação do Ministério da Saúde foi a Portaria $n^{\circ} 196$, a qual definiu o conceito de infecção hospitalar e determinou a criação de Comissões de Controle de Infecção Hospitalar, as CCIH, em todos os hospitais do território nacional. Através desse instrumento normativo, também se indicou como deveria atuar essas Comissões, traçando o modo de operação e os critérios a serem analisados pelas mesmas.

Essa portaria vigeu até a edição da Portaria n ${ }^{\circ}$ 930, de 27 de agosto de 1992, a qual manteve o mesmo objetivo de sua antecessora, traçar parâmetros a serem observados na aplicação de medidas de controle da infecção hospitalar. Mas, agora, de acordo com a Lei ${ }^{\circ}$ 8.080, de 19 de setembro de 1990, que instituiu o Sistema Único de Saúde (SUS). Passou a sujeitar os descumprimentos das normas relativas ao controle de infecção hospitalar, ao procedimento previsto na Lei $n^{\circ}$ 6.437/77 e não mais ao Decreto $\mathrm{n}^{\mathrm{o}} 77.052 / 76$.

Na seqüência, em 06 de janeiro de 1997, foi sancionada a Lei $\mathrm{n}^{\circ}$ 9.431, ainda em vigor, que dispôs sobre a obrigatoriedade da manutenção de programa de controle de infecções hospitalares pelos hospitais do País. Para regulamentar essa lei, foi expedida nova Portaria, de $\mathrm{n}^{\circ}$ 2.616/GM/MS, de 12 de maio de 1998, que ampliou as competências das CCIH e das comissões de execução, denominadas Serviços de Controle de Infecção Hospitalar (SCIH), criadas pela Portaria anterior.

Posteriormente, em 02 de junho de 2000, a Agência Nacional de Vigilância Sanitária (Anvisa), titular do Programa Nacional de Controle de Infecção Hospitalar (PNCIH) desde 1999, baixou a Resolução Anvisa RDC 48, que consiste em um roteiro de inspeção do programa de controle de infecção hospitalar. 
Além da legislação acerca do tema, o Ministério da Saúde em conjunto com a Anvisa (Agência Nacional de Vigilância Sanitária) publica manuais ${ }^{4}$ sobre o assunto e incentiva o debate em congressos e fóruns por todo o País. Toda medida de precaução e controle é bem vinda, diante da realidade que hoje se constata: quanto maior a tecnologia e as condições para aumentar o tempo de sobrevida dos pacientes, maiores os índices de infecção hospitalar, o que se agrava também pelo aumento da média de permanência dos pacientes nas instituições de saúde, situação que propicia o desenvolvimento de mais infecções. Não obstante, a ampliação do acesso da população a tratamentos e medicamentos, gera o uso indiscriminado de antibióticos, contribuindo também para o aumento do número de infecções.

Em 2004, com o intuito de oferecer aos hospitais e gestores de saúde uma ferramenta para o aprimoramento das ações de prevenção e controle das infecções relacionadas à assistência à saúde, a Anvisa lançou o Sistema Nacional de Informação para o Controle de Infecções em Serviços de Saúde (SINAIS).

Esse sistema que funciona com a entrada de dados e a emissão de relatórios em uma rotina de trabalho, acompanhando as atividades já desenvolvidas pelas $\mathrm{CCIH}$, permite o monitoramento da qualidade da assistência dos serviços de saúde no Brasil. A análise dos indicadores, obtidos de forma rápida e eficiente, permitirá a compreensão abrangente, ao mesmo tempo detalhada, do comportamento dessas infecções e do impacto das medidas de controle adotadas.

Contudo, esse sistema não vem cumprindo seu papel, em virtude da baixa adesão dos hospitais.

\section{DA RESPONSABILIDADE CIVIL HOSPITALAR}

A responsabilidade civil desdobra-se em duas modalidades: a responsabilidade subjetiva e a responsabilidade objetiva. Na primeira, perquire-se a culpa, na segunda pouco importa o elemento culpa, basta a prova do dano e do nexo causal.

A responsabilidade subjetiva é oriunda da teoria clássica e com a evolução das relações negociais e interpessoais vem perdendo espaço para a responsabilidade

\footnotetext{
${ }^{4}$ A exemplo disto foi publicado, no ano de 2005, o manual "Pediatria: prevenção e controle de infecção hospitalar", com o objetivo de divulgar as informações necessárias tanto à organização das unidades de saúde, quanto às práticas específicas dispensadas ao paciente em idade pediátrica pela equipe profissional.
}

(C) 2008. Departamento de Direito da UFSM. Todos os direitos reservados. 
objetiva. Junto com a modernidade expandiu-se a idéia de consciência social para com o meio ambiente, bem como para com as outras pessoas. Portanto, todos são responsáveis por suas condutas e seus atos, quaisquer que sejam estes, ainda que despidos da intenção de prejudicar ou de provocar danos.

Com a vigência da responsabilidade objetiva ampliou-se a segurança nos mais diversos setores, principalmente, no âmbito da relação de consumo. Aliás, com a introdução da Lei $\mathrm{n}^{\circ}$ 8.078, de 11 de setembro de 1990, a qual instituiu o Código de Defesa do Consumidor (CDC), teve início uma nova fase para as relações consumeristas. Prestadores de serviços e fornecedores de produtos tiveram sua responsabilidade demasiadamente alargada, o que aos poucos foi firmado pela jurisprudência e reforçado pelo Código Civil de 2002. E os consumidores, agora detentores de direitos, passaram a informar-se e a usarem de todas as suas prerrogativas. É claro que para isso contribuiu o Poder Público, não só com a edição da Lei, mas com a implantação de órgãos especializados, os Programas de Defesa do Consumidor (PROCONs), para atender esse público até então esquecido.

É nesse contexto que se insere a relação entre hospital e paciente, isto é, na fórmula "prestador de serviços versus consumidor". É isso mesmo, o paciente é um consumidor de serviços de saúde e, por isto, a ele é devido respeito, informação e qualidade de serviços e produtos.

Ainda quando se trate de hospitais públicos, admite-se a incidência das normas consumeristas, bem como não se afasta a aplicação da responsabilidade objetiva na maioria dos casos. O que é justificado pelo caput, do art. $3^{\circ}$ do $\mathrm{CDC}^{5}$, que incluiu no conceito de fornecedor também as pessoas jurídicas de direito público e pelo art. 22 do mesmo diploma legal.

A prática permitiu à doutrina classificar o contrato hospitalar em três espécies. Utiliza-se aqui a organização elaborada por Eduardo Dantas (2008, p. 02-03), advogado militante na área do Direito Médico.

\footnotetext{
${ }^{5}$ Art. $3^{\circ}$ Fornecedor é toda pessoa física ou jurídica, pública ou privada, nacional ou estrangeira, bem como os entes despersonalizados, que desenvolvem atividade de produção, montagem, criação, construção, transformação, importação, exportação, distribuição ou comercialização de produtos ou prestação de serviços.

Art. 22. Os órgãos públicos, por si ou suas empresas, concessionárias, permissionárias ou sob qualquer outra forma de empreendimento, são obrigados a fornecer serviços adequados, eficientes, seguros e, quanto aos essenciais, contínuos.

Parágrafo único. Nos casos de descumprimento, total ou parcial, das obrigações referidas neste artigo, serão as pessoas jurídicas compelidas a cumpri-las e a reparar os danos causados, na forma prevista neste código.
} 
Contrato direto e integral firmado entre hospital e paciente que procura os serviços da instituição, responsabilizando-se esta por todos os procedimentos médicos, cirúrgicos, anestésicos, etc. e ainda pela prestação de serviços laboratoriais, consultas e internações. Nessa hipótese, os profissionais que atendem o paciente são prepostos da instituição.

Contrato firmado com a entidade hospitalar, em razão da busca do paciente pelo atendimento de determinado profissional de saúde, que o acolhe ou atende na instituição em que pratica sua atividade, seja por vínculo direto, ou pertencendo ao seu quadro clínico de referência.

Nesse caso, entende-se ser possível a responsabilização (solidária entre hospital e médico ou direta, a critério do próprio paciente-consumidor). Afinal, quando o médico ou outro profissional oferece um serviço, o qual necessariamente dever ser prestado em um determinado local (hospital ao qual está vinculado), conclui-se que o profissional está recomendando a instituição, ao menos, é o que se presume, pois elegeu a mesma como centro habitual do desempenho de suas funções.

Basta pensar que, se o serviço fosse oferecido em consultório ou clínica particular, o profissional seria responsável por qualquer evento danoso que acometesse o paciente enquanto ele lá estivesse. Portanto, porque o serviço é prestado em um hospital, a responsabilidade do profissional não deve ser minorada.

Há também o contrato de internamento, em que o hospital responsabiliza-se por todos os serviços acessórios (enfermagem, anestesia, instalações, incolumidade, guarda, etc.) à atividade principal, a qual é desenvolvida por médico não necessariamente vinculado à instituição. O médico ou o paciente escolhem o nosocômio que entenda mais adequado ao tratamento ou à intervenção cirúrgica.

Observa-se nessa última modalidade de contrato, que o médico e o hospital terão responsabilidades distintas e autônomas, cada um respondendo pelos serviços que prestou.

Em que pese os diferentes tipos de contrato hospitalar, conclui-se que em todos eles a responsabilidade do nosocômio, no que tange à infecção hospitalar, é objetiva, porque a infecção, ou melhor, a ausência desta, está diretamente ligada ao padrão de excelência dos serviços prestados pelo estabelecimento de saúde. 
Ressalva-se que o médico poderá ser solidariamente responsável com o hospital, nos casos de infecção hospitalar, quando a sua conduta foi preponderante para a instalação da infecção.

A responsabilidade objetiva do hospital decorre do tipo de obrigação que se compromete a prestar/cumprir ao paciente, no momento da contratação, qual seja, obrigação de meio. Nesse ponto, vale ressalvar que o contrato firmado dispensa qualquer formalidade ou pressuposto especial, podendo, portanto, se dar de forma verbal, escrita, expressa, tácita, onerosa ou gratuita.

A obrigação de meio significa que a empresa ou o profissional responsabiliza-se por todas as etapas da prestação de serviço, podendo ser acionado judicial ou extrajudicialmente caso alguma fase da obrigação não se revele consentânea com os padrões normais esperados. Em sentido oposto segue a obrigação de resultado, pela qual só poderá ser postulada reparação ou indenização do responsável, no caso do resultado prometido não ter sido alcançado.

A obrigação assumida pelos hospitais, via de regra, é de meio, porque o estabelecimento de saúde não promete a cura, o sucesso do tratamento ou qualquer resultado. Obriga-se sim, a prestar atendimento adequado, de qualidade, utilizando-se de profissionais competentes, das melhores e mais avançadas técnicas, mas nada promete quanto ao êxito da intervenção.

Quanto à responsabilidade objetiva, para o episódio de infecção hospitalar, os operadores jurídicos são praticamente unânimes. Contudo, há quem defenda a responsabilidade objetiva na modalidade da teoria do risco, mais especificamente da teoria do risco criado, pela qual o dever do agente de indenizar decorre simplesmente do risco gerado pelo exercício da sua profissão ou do desenvolvimento de determinada atividade.

Enquanto outra corrente defende a responsabilidade objetiva na modalidade de presunção de culpa, a qual poderá ser afastada pelo estabelecimento de saúde se provada a ausência de culpa, isto é a ocorrência de uma causa excludente de sua responsabilidade, que de antemão é presumida.

Parece mais consentânea com os primados da justiça a segunda posição. Pois, permite que o nosocômio desincumba-se do ônus indenizatório, quando não concorreu para a superveniência do evento lesivo. Destaca-se aqui, que o contrato hospitalar não pode ser interpretado como qualquer outro contrato de consumo, vez que seu objetivo 
primordial, trate-se de estabelecimento público ou particular, não é o lucro, mas a assistência à saúde.

Em vista disso, entende-se que o parágrafo único do art. 927 do Código Civil que consagra a responsabilidade objetiva e a teoria do risco, bem como o art. $14, \S 1^{\circ}$ do CDC e seus incisos não podem ser interpretados sem levar em conta as peculiaridades do contrato hospitalar. Em se tratando de infecção hospitalar, deve ser considerada, principalmente, a impossibilidade de se obter índice zero de infecção e a influência determinante das condições do paciente para a ocorrência da infecção.

A par do exposto, conclusão lógica é que a contração de infecção hospitalar é causa justificante da propositura de ações de responsabilidade civil. Assim, o controle da infecção institucional é medida imprescindível para assegurar a saúde dos pacientes, a reputação do nosocômio e a economia de recursos destinados às indenizações dos ofendidos.

\section{O CONTROLE DE INFECÇÃO HOSPITALAR E SUA REPERCUSSÃO NA DETERMINAÇÃO DA RESPONSABILIDADE CIVIL E NA FIXAÇÃO DO QUANTUM INDENIZATÓRIO}

Importante questão a ser respondida é se o controle de infecção hospitalar e, por conseguinte, os índices obtidos pelo hospital podem reduzir o montante indenizatório ou até mesmo excluir a responsabilidade do estabelecimento.

A despeito da maioria das decisões da jurisprudência decorrer de um julgamento apressado e extremamente protetivo do consumidor, parte geralmente hipossuficiente técnica e/ou economicamente, mas por vezes não detentora da razão, sempre é tempo de mudar, máxime, quando se tem em vista o aprimoramento da exegese legal e a busca pela justiça.

\subsection{Hipóteses de exclusão da responsabilidade}

Conforme já mencionado, a responsabilidade do hospital pela infecção nosocomial é eminentemente objetiva, podendo se dar na modalidade de presunção de culpa ou aplicação da teoria do risco. Por se tratar de uma responsabilidade contratual, decorrente de uma operação de consumo há incidência do CDC, mais precisamente o seu art. 14. Bem como poderá ser aplicado o inciso VIII, do art. $6^{\circ}$ do Diploma 
Consumerista e ser invertido o ônus da prova, quando, a critério do juiz, for verossímil a alegação do paciente-consumidor ou quando este apresentar-se hipossuficiente, segundo as regras ordinárias da experiência, para produzir as provas necessárias.

A análise do já referido art. 14 revela as hipóteses em que a responsabilidade civil do prestador do serviço, no caso, o hospital, poderá ser afastada, veja-se, pois.

Antes, mister destacar que, conforme DANTAS (2008, p. 04), as instituições hospitalares, ainda que respondam sem culpa (e dentro de determinadas condições), não podem responder sem causa. Em outros termos, o contrato de prestação de serviços hospitalares, embora se trate de um contrato misto, que envolve diversas obrigações não se equipara a um contrato de seguro. Assim, uma vez provado pelo nosocômio a realização de todos os procedimentos e providências cabíveis para evitar a infecção hospitalar, eventual infecção contraída pelo paciente não pode gerar automaticamente o dever de indenizar, pois, então, estar-se-ia imputando à instituição uma responsabilidade sem causa. O dever de reparar apenas deverá ser imputado ao hospital, se o pacienteconsumidor comprovar que este falhou no seu dever de precaução.

A esse respeito leciona com proficiência Jurandir Sebastião (2006, p. 39):

Bem examinado, ao invés de contrato de seguro de saúde, como querem os desavisados, um hospital é sempre um verdadeiro "centro de doenças", as mais diversas e imprevisíveis, conhecidas e desconhecidas até o momento de sua eclosão. Daí os riscos para todos: pacientes já internados; acompanhantes; visitas; médicos; enfermeiros; funcionários burocráticos; serviçais, etc. Por isso, inúmeras são as cautelas a cumprir, impostas por regras de saúde pública, com vistas à prevenção geral. Cumpridas as regras estabelecidas de profilaxia técnica e pessoal, o risco de contaminação (que pode ocorrer dos germes naturais do próprio paciente) e seqüente infecção não podem ser interpretados como risco empresarial, a impor, por isso mesmo, indenização pelo critério de responsabilidade sem culpa - como é a regra genérica, literal, do art. 14, caput, do CDC.

\subsubsection{Ausência de defeito na prestação do serviço}

O $\S 1^{\circ}$, do art. 14 diz que o serviço será defeituoso quando não fornece a segurança que o consumidor dele pode esperar, devendo ser considerada três circunstâncias relevantes: (1) o modo de fornecimento o serviço; (2) o resultado e os riscos que razoavelmente dele se esperam; e (3) a época em que foi fornecido.

A par desse texto legal combinado com o $\S 3^{\circ}$ do mesmo artigo, o qual explica que o fornecedor não será responsabilizado quando inexistente defeito no serviço, 
conclui-se que se o nosocômio comprovar que seguiu a risca as exigências sanitárias da Lei n $n^{\circ}$ 9.431/97 e, principalmente, da Portaria do Ministério da Saúde de nº 2.626/98. Tendo, com isto, logrado êxito no controle de infecção hospitalar e obtido a redução dos índices de infecção no estabelecimento, por certo que defeito do serviço não há e, conseqüentemente, deverá ser afastada a responsabilidade do fornecedor.

Destaca-se que a eficácia das medidas de prevenção e controle da infecção nosocomial não significa índice zero ou nulo de infecções, pois isto é impossível. No entanto, que a própria Portaria retro citada, em seu anexo I, item $1^{6}$ preleciona a "redução máxima possível da incidência e gravidade das infecções hospitalares" e não a erradicação da mesma.

Impossibilidade que é confirmada por estudo realizado pelo Instituto Brasileiro de Defesa do Consumidor (IDEC), o qual deu origem ao relatório $O$ Controle de Infecção Hospitalar no Brasil e os Consumidores: "Embora não exista uma taxa zero de infecção, pois existem aquelas que dependem muito do estado do paciente, estudos indicam que um programa de controle de infecção hospitalar bem conduzido reduz em $30 \%$ a taxa de infecção do serviço". (grifo nosso)

Justamente, por, na maioria dos casos, o desenvolvimento da infecção hospitalar depender do próprio paciente, é que não pode ser imputada ao nosocômio responsabilidade objetiva, segundo a teoria do risco, visto que o estabelecimento de saúde não pode recusar pacientes ou escolher doentes.

No mesmo diapasão, segue o parecer técnico-científico da Dra. Cristina Hueb Barata, professora adjunta da cadeira de Infectologia da UFTM e Luci Regina Brito Ribeiro, enfermeira mestranda em Controle de Infecção Hospitalar (apud SEBASTIÃO, 2006, p.40):

Como se vê, o controle das infecções hospitalares não depende exclusivamente da equipe médica hospitalar, mas de uma interação das medidas preventivas e do "status" imunológico do paciente. Em algumas situações, o cumprimento das medidas preconizadas pela CCIH pode prevenir essas infecções; em outras, embora corretamente realizadas, não são suficientes para evitar o aparecimento de infecções, o que muitas vezes leva à frustração na relação médico-paciente, com aparência de que não houve correto cumprimento do contrato.

\footnotetext{
6 "l. O Programa de Controle de Infecções Hospitalares (PCIH) é um conjunto de ações desenvolvidas deliberada e sistematicamente, com vistas à redução máxima possível da incidência e da gravidade das infecções hospitalares."
} 
Seguindo a análise da Portaria supra, verifica-se também que a disposição legal em exame afasta o defeito do serviço, quando comprovado que os riscos suportados pelo consumidor estavam dentro dos padrões de normalidade. Assim, percebe-se que a exclusão da responsabilidade da instituição hospitalar pode advir da prova de que o risco de infecção hospitalar a que ficou exposto o paciente não extrapolou os parâmetros da normalidade, tendo em vista a média dos índices dos nosocômios da região.

Portanto, eventual infecção hospitalar contraída pelo paciente decorrerá de risco inerente à situação, pois impossível excluí-lo totalmente, com as técnicas atualmente adotadas e a tecnologia disponível.

Nesse sentido, há precedente pretoriano do Tribunal de Justiça do Estado de Minas Gerais, excluindo a responsabilidade do hospital com base em dois fundamentos, o ótimo padrão de controle de infecção hospitalar pela instituição e a culpa exclusiva da paciente-consumidora. Seguem alguns trechos desse julgado, em função do alto teor ilustrativo:

AÇÃO DE REPARAÇÃO POR DANOS FÍSICO E ESTÉTICO DECORRENTES DE PARTO INDEFERIMENTO DE PROVA - AUSÊNCIA DE INTERPOSIÇÃO DO RECURSO CABÍVEL - PRECLUSÃO - CERCEAMENTO DE DEFESA - INOCORRÊNCIA - AUSÊNCIA DE ABERTURA DE PRAZO PARA OFERECIMENTO DE RAZÕES FINAIS - INEXISTÊNCIA DE PREJUÍZO - NULIDADE AFASTADA - NEGLIGÊNCIA HOSPITALAR A PROVOCAR INFECÇÃO HOSPITALAR CONSUBSTANCIADA NA NÃO ADEQUADA ASSEPSIA NA SALA DE CIRURGIA - AUSÊNCIA DE PROVA - DEFEITO NO SERVIÇO INOCORRÊNCIA - RESPONSABILIDADE CIVIL AFASTADA - INTELIGÊNCIA DO ART. $14, \S 3^{\circ}$, INCISO I, DO CODECON - SENTENÇA MANTIDA.

(...)

Correta, pois, a colocação do Juiz monocrático, inclusive no que respeita à inexistência de defeito quanto aos serviços prestados pelo nosocômio-apelado, pois, na dicção do ilustre Expert do Juizo, o documento de f. 519

"confirma que o padrão de controle de Infecção Hospitalar está dentro dos melhores padrões, pois em 1476 atos cirúrgicos, de todas as especialidades, realizada na Ré, durante o ano de 1993, houveram apenas 05 intercorrências de infecção ao nível cutâneo" (f. 545), acrescentando que havia "ainda que considerar que houveram 78 casos de infecção na clínica ginecológica $e$ obstétrica - infecções em ferida cirúrgica - num universo de 1476 atos cirúrgicos, corresponde a 5,28\% (fls. 518 e 523 dos autos)." (f. 545)

(...)

Não comprovada, pois, a negligência hospitalar na falta de adequada assepsia na sala de cirurgia, ou melhor, demonstrada a adoção da técnica médica

(c) 2008. Departamento de Direito da UFSM. Todos os direitos reservados. 
exigivel, não pode pretender a autora sucesso na sua empreitada judicial buscando reparação de prejuízos sofridos, como deflui do art. $14, \S^{\circ}$, inc. I, do Estatuto Consumerista.

(TJ MG, Processo $n^{\circ}$ 2.0000.00.411140-4/000(1), Relator: Osmando Almeida, Julgado em: 23/03/2004, Publicado em: 24/04/2004.)

O Tribunal de Justiça do Estado do Rio Grande do $\mathrm{Sul}^{7}$ também já afastou a responsabilidade do nosocômio, diante da inexistência de nexo de causalidade entre a septicemia e a morte do paciente, pois entendeu que a infecção hospitalar que fundamenta o dever de indenizar é aquela previsível, decorrente da falta de condições necessárias para um tratamento adequado.

A defesa das excludentes de responsabilidade por certo que beneficiam as instituições de saúde, mas visa, na verdade, evitar a inviabilidade da prática médica em nosocômios, de modo que toda e qualquer infecção fique sujeita à indenização, mesmo quando o hospital esmerou-se na criação e implantação de seu Programa de Controle de Infecção Hospitalar (PCIH). Inviabilidade que repercutirá diretamente no preço dos serviços médicos, dificultando ainda mais o acesso à saúde, afinal, a cobertura do risco deverá ser remunerada. Assim, como contribuirá para agravar fato social negativo já observado atualmente, a escassez de hospitais. Pois, se os empreendedores convencerem-se de que o risco de prejuízos e até mesmo de falência do negócio é superior às expectativas de êxito, certamente que não investirão no seguimento.

Outra razão é que embora o paciente-consumidor seja a parte hipossuficiente da relação contratual, isso não pode ser traduzido em imediata procedência das ações indenizatórias. Se não, desnecessária seria a ação de conhecimento, podendo ser ajuizada diretamente a execução em face da entidade hospitalar, bastando apresentar prova da prestação do serviço, o que serviria de título executivo extrajudicial.

\subsubsection{A culpa exclusiva do paciente-consumidor ou de terceiro}

Outra hipótese de exclusão da responsabilidade é apresentada no inciso II, do art. 14, do CDC, a saber, a culpa exclusiva do consumidor ou de terceiro.

Há casos de infecção hospitalar que podem ser imputados exclusivamente ao paciente ou a terceiro.

\footnotetext{
${ }^{7}$ Apelação Cível No 70006260152, Quinta Câmara Cível, Relator: Leo Lima, Julgado em 13/11/2003.

(C) 2008. Departamento de Direito da UFSM. Todos os direitos reservados.
} 
Exemplos de infecções decorrentes de culpa exclusiva da vítima são as infecções comunitárias, que são aquelas já presentes no momento em que o paciente internou no hospital, podendo, inclusive, estarem em incubação e aparecerem os sintomas somente após a internação. Bem como também são consideradas infecções comunitárias aquelas associadas com complicações ou extensões de infecção existente no ato de admissão; as infecções em recém-nascidos, cuja aquisição via transplacentária é conhecida ou foi comprovada e tornou-se evidente logo após o nascimento, como a herpes simples, a AIDS e a sífilis e aquelas que acometem recém-nascidos associadas com bolsa rota superior a 24 horas.

Quanto à culpa exclusiva de terceiro, tem-se como exemplo a infecção hospitalar adquirida em outro nosocômio.

Assim, ocorrendo uma dessas hipóteses, de plano, deve ser alijada a responsabilidade da instituição nosocomial acionada, não comportando juízo de valor ou discricionário do magistrado, vez que se trata de expressa excludente legal.

\subsubsection{O caso fortuito e a força maior}

Por fim, importa mencionar o caso fortuito e o de força maior como excludentes da responsabilidade civil. Alguns Tribunais não admitem essas causas como eximentes da responsabilidade do hospital-fornecedor, alegando que as mesmas se inserem na área de risco a ser suportada por quem desenvolve a atividade. Porém, considerando que em todos os demais casos de responsabilidade civil há aceitação, não há razão para dispensar tratamento diverso quando se tratar de responsabilidade de nosocômio por infecção hospitalar. Principalmente, porque se tratam de eventos totalmente aleatórios, que escapam à previsão técnica e ao controle humano, não sendo possível evitar.

Favorável à admissão dessas situações como excludentes do dever de indenizar, manifestou-se o Tribunal de Justiça do Estado o Rio Grande do Sul:

RESPONSABILIDADE CIVIL. MORTE POR INFECÇÃO CONTRAÍDA EM HOSPITAL. ENTIDADE HOSPITALAR, PESSOA JURÍDICA. APLICAÇÃO DOS PRECEITOS CONTIDOS NO CÓDIGO DO CONSUMIDOR. E O HOSPITAL, PESSOA JURÍDICA, CIVILMENTE REPONSÁVEL PELA REPARAÇÃO POR DANOS MATERIAIS E MORAL SOFRIDOS POR FAMILIARES DE PESSOA QUE, POR INFECÇÃO HOSPITALAR CONTRAÍDA DURANTE INTERNAMENTO, VIER A MORRER. HOSPITAL QUE NÃO PRESTA APENAS SERVIÇOS DE HOTELARIA, MAS FORNECEDOR DO EQUIPAMENTO E INSTRUMENTAL CIRÚRGICO, 
EMPREGADOR DO CORPO DE FUNCIONARIOS, MESMO GRADUADOS, ALÉM DE CREDENCIADOR DO CORPO MÉDICO, SENDO, CONSEQUENTEMENTE, RESPONSÁVEL POR TUDO O QUE OCORRER NO PERÍODO DE INTERNAMENTO DO PACIENTE, INCLUSIVE E ESPECIALMENTE NO CAMPO DA REPONSABILIDADE POR DANO QUE DECORRE A SAÚDE OU VIDA DO PACIENTE. RESPONSABILIDADE SÓ AFASTADA SE O DANO DECORRER DO IMPONDERÁVEL, DO FORTUITO OU FORÇA MAIOR, CAUSAS EXTERNAS E EXCLUDENTES DE RESPONSABILIDADE. ADEMAIS, ENTIDADES PRESTADORAS DE SERVIÇOS, ESTA, O HOSPITAL, SUJEITO AO CÓDIGO DO CONSUMIDOR - LEI 8.078, DE 11 DE SETEMBRO DE 1990 INCLUSIVE NO QUE DIZ COM A INVERSÃO DO ÔNUS DE PROVAR E AO PRINCÍPIO DA RESPONSABILIDADE OBJETIVA. DANOS PATRIMONIAIS. DESPESA HOSPITALAR E PENSIONAMENTO DEVIDO. DANO MORAL. DEVIDO INCLUSIVE A MENOR RECÉM NASCIDO, SENDO SUA MÃE A VÍTIMA DA INFECÇÃO HOSPITALAR CONTRAÍDA QUANDO DA REALIZAÇÃO DO PARTO CIRÚRGICO. ACAO DE REPARAÇÃO POR DANOS MATERIAIS E MORAL JULGADA IMPROCEDENTE EM INSTÂNCIA INICIAL. PROVIMENTO DO APELO DOS AUTORES, COM A PROCEDENCIA DA ACAO. (Apelação Cível No 595060146, Sexta Câmara Cível, Tribunal de Justiça do RS, Relator: Osvaldo Stefanello, Julgado em 19/12/1995) (grifo nosso)

\subsection{Redução do quantum indenizatório}

Indubitável que se a manutenção do $\mathrm{PCIH}$, com resultados satisfatórios, se não servir para excluir a responsabilidade do nosocômio, no mínimo, configurará causa atenuante da responsabilidade, refletindo diretamente no quantum indenizatório.

Ora, se a entidade hospitalar preocupa-se com a saúde de seus pacientes, observandos as regras definidas pelo Ministério da Saúde e da Anvisa é porque age com cautela e perícia. A implantação da CCIH, responsável pelo planejamento das ações, e do SCIH, a quem incumbe a execução das ações, demonstra que a entidade age com prudência, cautela e técnica, preocupando-se com o controle e a manifestação de novos casos de infecções.

Diante desse quadro, só será imputável alguma responsabilidade ao nosocômio, se este não comprovar a ausência de culpa, demonstrando que fez uso de todas as técnicas e tecnologias disponíveis para assegurar a máxima assepsia do local.

\section{CONSIDERAÇÕES FINAIS}

De todo o exposto, conclui-se que o controle de infecção hospitalar apresenta fundamental importância, observa-se:

(C) 2008. Departamento de Direito da UFSM. Todos os direitos reservados. 
- para a saúde dos pacientes-consumidores e a conseqüente confiança na instituição de saúde e nos serviços prestados;

- para a imagem e reputação do nosocômio perante a comunidade e junto ao Ministério da Saúde, da Anvisa e das Secretarias Estadual e Municipal de Vigilância Sanitária, pois cumprida as normas técnicas com eficiência, evitando a intervenção dos órgãos de saúde na instituição, bem como a aplicação de multas pecuniárias, de interdição, etc.;

- para o orçamento do hospital, pois evitados danos aos pacientes, impede-se ações judiciais onerosas e indenizações elevadas.

Nessa senda, afere-se que a implantação do PCIH e a obtenção de índices satisfatórios do controle da infecção podem ser consideradas como causa de exclusão da responsabilidade nosocomial, assim como a culpa exclusiva da vítima ou de terceiro, o caso fortuito e de força maior, pois ausente defeito na prestação do serviço. $\mathrm{Ou}$, ao menos, implicarão em atenuação da responsabilidade, uma vez que a mesma é objetiva, dada a relação de consumo travada ente paciente e hospital, de modo que permitirá a redução do montante indenizatório.

Por fim, ressalta-se a incidência das disposições do Código de Defesa do Consumidor e subsidiariamente as do Código Civil, pois a relação paciente versus hospital é de consumo por excelência, mesmo que se trate e instituição pública de saúde.

\section{REFERÊNCIAS BIBLIOGRÁFICAS}

DANTAS, Eduardo. Responsabilidade civil hospitalar: breves notas doutrinárias e jurisprudenciais. In: Instituto Paulista de Estudos Bioéticos e Jurídicos. Disponível em: $<$ http://www.ipebj.com.br/index.php?option=com_content\&task=view\&id=286\&It emid=51>. Acesso em: 05 maio 2008.

GONÇALVES, Carlos Roberto. Responsabilidade Civil. 9a ed. São Paulo: Saraiva, 2005 .

GRINOVER, Ada Pellegrini... [et al]. Código Brasileiro de Defesa do Consumidor: Comentado pelos Autores do Anteprojeto. $9^{\mathrm{a}}$ ed. Rio de Janeiro: Forense Universitária, 2007. 
Instituto Brasileiro de Defesa do Consumidor - IDEC. O Controle de Infecção Hospitalar no Brasil e os Consumidores. São Paulo: 2006. Disponível em: http://www.idec.org.br/arquivos/relatorio_ih.pdf. Acesso em: 08 maio 2008.

MARQUES, Claudia Lima. Contratos no Código de Defesa do Consumidor: o novo regime das relações contratuais. $5^{\mathrm{a}}$ ed. São Paulo: Editora Revista dos Tribunais, 2005.

PILATI, José Isaac. Aspectos jurídicos no controle de infecção hospitalar. Disponível em: http://www.hospitaldecaridade.com.br/informativos/coluna/docs/infechosp.pdf Acesso em: 07 maio 2008.

SEBASTIÃO, Jurandir. Responsabilidade civil médico/hospitalar e o ônus da prova. Revista Jurídica UNIJUS. Uberaba: UNIUBE, v. 1, n.1, 1998.

SOUZA, Neri Tadeu Camara. Responsabilidade civil do hospital. Jus Navigandi, Teresina, ano 6, n. 54, fev. 2002. Disponível em: <http://jus2.uol.com.br/doutrina/texto.asp?id=2638>. Acesso em: 07 maio 2008.

VENOSA, Sílvio de Salvo. Direito Civil: Responsabilidade Civil. $5^{\text {a }}$ ed. São Paulo: Atlas, 2005. 